\title{
Interning for the Mathematics Resources Centre at the University of Bath - a student reflection
}

Emma Collins-Jones, The University of Bath, The Mathematics Resources Centre, Bath, U.K. Email: ecj26@bath.ac.uk

\begin{abstract}
In the summer of 2015, sigma and the Mathematics Resources Centre funded three student internships at the University of Bath to look at a student-centred approach to promoting a mathematics support centre. A recent graduate of BSc Sport \& Exercise Science, I worked on this project alongside Lynn Luong (BSc Economics) and Inès Righi (BSc Politics with Economics). In this short article, I will reflect upon my experience.
\end{abstract}

\section{Background}

The Mathematics Resources Centre at the University of Bath, also known as MASH (Mathematics and Statistics Help), offers help with mathematics and statistics for all students. The MASH Coordinator, Dr Cheryl Voake-Jones, supervised the internship, and she was my first point of call in learning all about MASH. MASH offer many services, including general drop-ins, a one to one Statistics Advisory Service (SAS), and peer mentored sessions. The team also deliver lecture content on many courses, as well as working with the Students' Union to host skills workshops and a weekly puzzles café.

During my four years at University, I had made use of SAS to get help with my final year project. However I thought the drop-ins were for maths students only, and I was unware of all of the other services! I was therefore both surprised and impressed to learn more about MASH; the need for more effective promotion to students was clear.

\section{Our project}

As part of my initial research for the project, I wanted to understand what did and didn't work in terms of promotion. As well as talking to students, I spoke to University staff and other professional services including the Writing Centre and Careers Service. Distributed via the sigma mailing list, a survey was also sent out to other maths support centres. Thank you to everyone who replied. Many colleagues commented that they also had difficulty promoting their services to students and social media was highlighted as something that many centres, as well as $\mathrm{MASH}$, wanted to start using but didn't know how or felt constrained by time.

Project activities included (but were not limited to) enhancing MASH's profile on social media, making a promotional video, and developing the range of posters used across campus. I had experience of managing social media in my part time job, and on my placement year, and therefore took the lead on this. However, I learnt a lot from bouncing ideas around with Cheryl, Inès and Lynn, and we all had slightly different thinking about how things should be done and had to work out the best strategy for MASH.

Facebook and Twitter were chosen as our social media platforms of choice, as they were already being used by other professional services on campus, as well as widely used by students. I was keen to establish a 'brand' for MASH and this was done by being consistent with eye-catching branded images on Facebook and Twitter. In terms of content and interacting with students, previously the posts had been sporadic, but it was decided that MASH should put out content every 
day. I set up a Hootsuite account, which enables the posts to be scheduled easily. Hootsuite (https://hootsuite.com/) is a social media management dashboard, and I would recommend it to anybody using more than one social media platform.

Since starting this project, our social media profiles have been transformed. Posts include not just MASH events but anything interesting that's going on, both on and off campus (public lectures, online courses, Students' Union news, ...). and every Friday, MASH posts a maths joke or pun (see Figure 1). One of Cheryl's initial concerns was whether we would have enough content to post about, but the reality is that once you start looking, there is plenty out there. In two months, MASH went from less than ten friends on Facebook and followers on Twitter, to 490 Facebook friends and 160 Twitter followers. As a result of this project, MASH now ask students how they knew about the service when they first attend a drop-in, so that they know how effective their different promotional strategies are. It's been pleasing to see students reporting Facebook and Twitter.

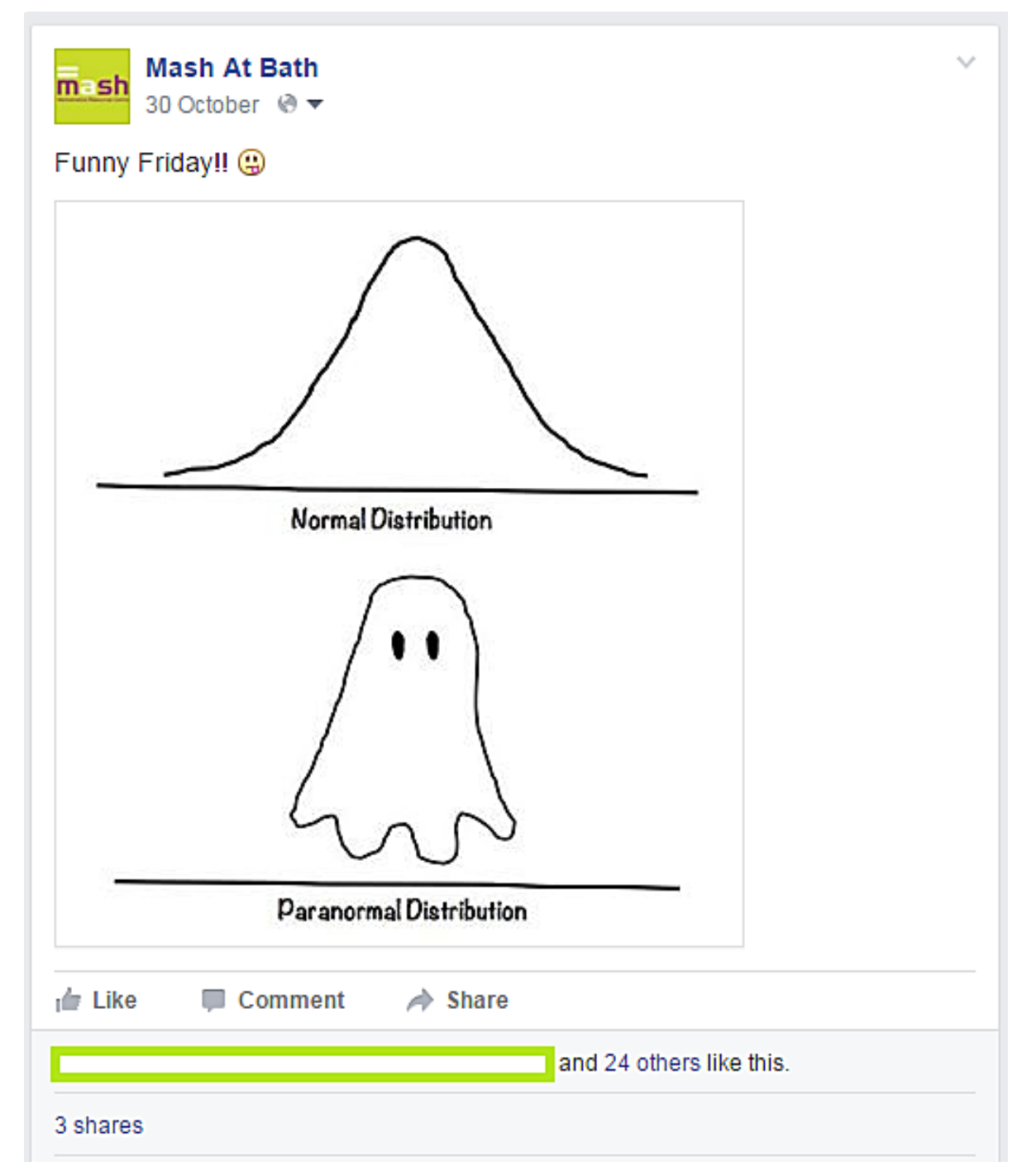

Figure 1. Example Facebook post

To follow MASH on social media, search 'Mash At Bath' on Facebook, and @BathMASH on Twitter.

\section{On our travels}

During the internship, Cheryl and I were invited by Dr. Ciarán Mac an Bhaird, Lecturer and Maths Support Centre Manager at Maynooth University, to present at the Irish Mathematics Learning 
Support Network Workshop on using Social Media to Promote Services. This was a great opportunity for me to gain experience presenting and, although somewhat nerve wracking to present to a room of academics having just finished my undergraduate degree, I was confident that the work we had done with social media at MASH was worth sharing. I presented on the practical aspects of social media, defining terms such as 'likes' and 'shares'. I didn't go through a PowerPoint but instead did somewhat of a virtual tour of Facebook and Twitter (where to post, search for contacts etc). Questions, and playing around on laptops, was encouraged and this approach made the session interactive and less boring (hopefully). Despite the early start (we flew to Ireland and back again the same day), it was great to meet colleagues from different universities and Ciarán gave us a fun tour around Maynooth!

Another great opportunity was to present as part of the student plenary session at the 2015 CETLMSOR conference at The University of Greenwich (see Figure 2). Being at the conference gave me a broader insight into maths support, and I enjoyed meeting not only staff but students from other universities who had been interning that summer. I was impressed by the broad range of projects being worked on. Lynn, Inès and I received lots of positive feedback about the work we presented, and we noticed other institutions setting up social media accounts after our talk. It has been really rewarding to have worked on a project that helps not only MASH at the University on Bath, but other institutions too.

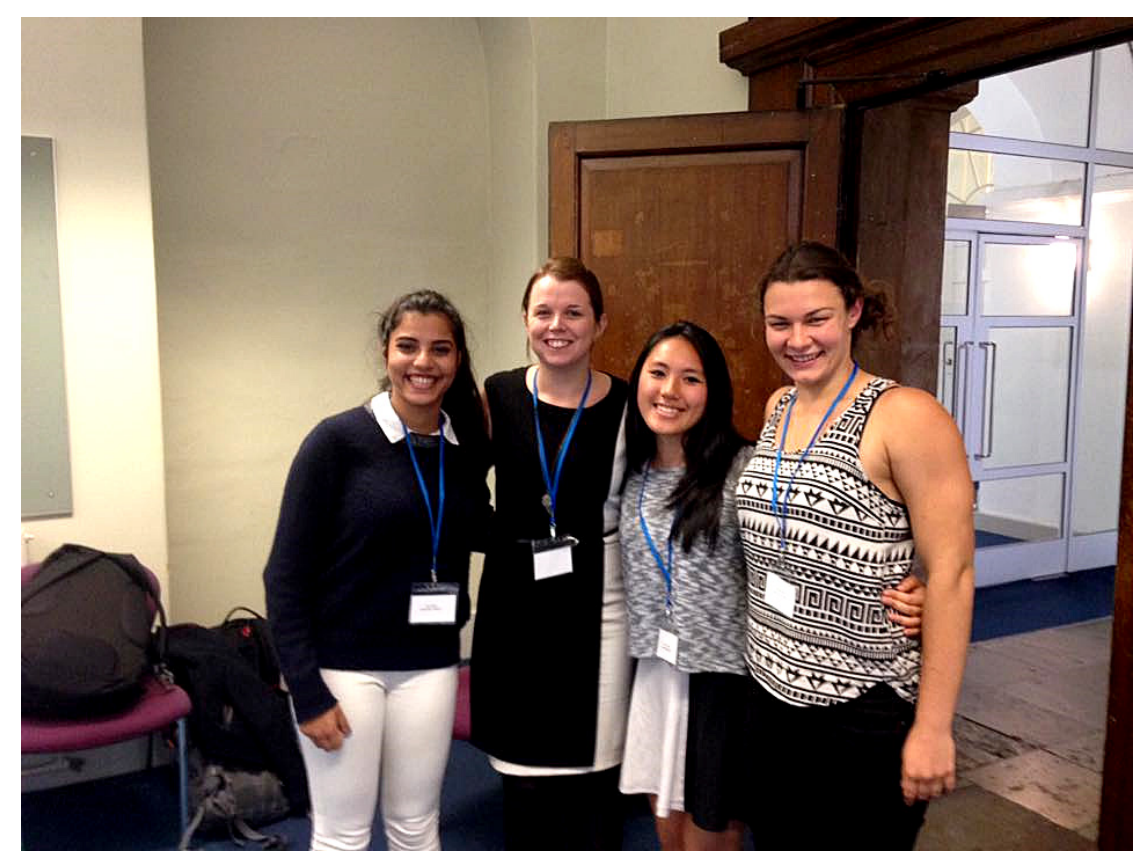

Figure 2. Inès, Cheryl, Lynn and Emma (from left to right). Smiles all round after our CETL-MSOR presentation.

\section{Personal benefits}

My internship with MASH was eye-opening and rewarding. The experience of going from student to staff in the University was very empowering. I enjoyed setting up meetings with different departments, presenting, and working creatively with the other interns. I was able to put some of the skills I learnt in my degree into practice; for example analytical and problem solving, and could use my experience as a student to make meaningful contributions. I even got to use the staff canteen!

A benefit from my internship is that MASH now employ me for a few hours a week to manage their social media, among other tasks. My supervisor, Cheryl, lists ideas for things to post on social media and then I spend an hour or two a week writing them in a student friendly way, creating images, researching other articles, etc. Using Hootsuite (mentioned earlier), I can schedule the posts to go 
out at different times each day. Furthermore, I have also been approached by sigma to deliver more social media workshops and to look further into the use social media in maths support.

\section{Next steps}

A social media guide is being put together which will cover the very basics of what social media is and how to use it, as well as how best to engage with students (and other academics and services). I hope other centres can take the lead from MASH and increase their social media presence to engage more students and help them with maths and stats.

\section{Acknowledgements}

I would like to thank sigma and MASH (in particular my supervisor Cheryl) for giving me this opportunity. 